\title{
Erratum to: Association between routine laboratory tests and long-term mortality among acutely admitted older medical patients: a cohort study
}

Henrik Hedegaard Klausen ${ }^{1 *}$, Janne Petersen ${ }^{1,2}$, Thomas Bandholm ${ }^{1,3,4}$, Helle Gybel Juul-Larsen ${ }^{1}$, Juliette Tavenier ${ }^{1}$, Jesper Eugen-Olsen ${ }^{1}$ and Ove Andersen ${ }^{1,5}$

\section{Erratum}

After the publication of this work [1] it was noticed that Fig. 2 is Fig. 3 duplicated. The correct figure is shown below.

\footnotetext{
* Correspondence: Henrik.Klausen@regionh.dk

'Optimed, Clinical Research Centre, Copenhagen University Hospital,

Hvidovre, Denmark

Full list of author information is available at the end of the article
} 

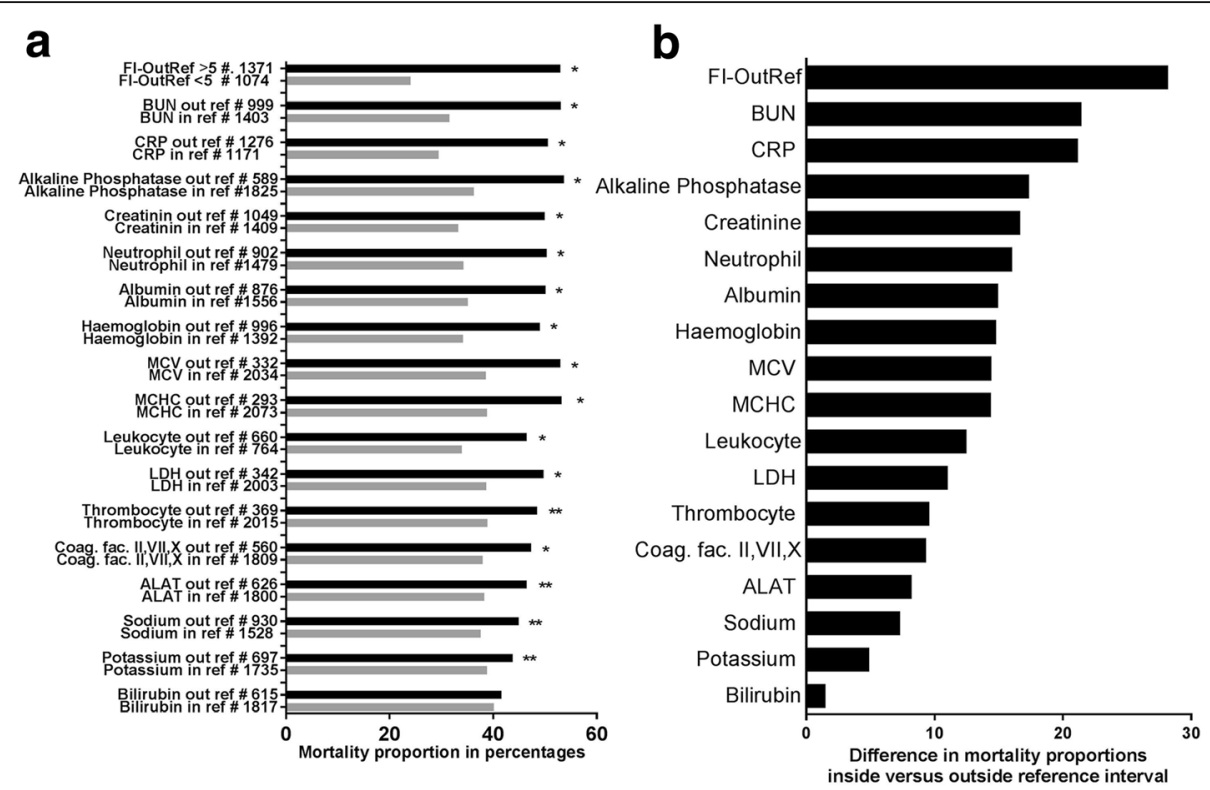

Fig. 2 a The number (\#) of patients with admission laboratory test results outside (out) or inside (in) the reference interval (ref) and their corresponding proportion of mortality within 3 years from discharge. Significance of difference by Chi-Square ${ }^{*} \sim P \leq 0.001,{ }^{* *} \sim P \leq 0.05$. $\mathbf{b}$ differences in the mortality proportion for patients inside versus outside the reference interval. Fl-OutRef: Frailty index by the number of admission laboratory test results outside the reference interval. MCHC: Mean corpuscular haemoglobin concentration. MCV: Mean corpuscular volume. BUN: Blood urea nitrogen. ALAT: Alanine aminotransferase. LDH: Lactate dehydrogenase. Coag. Fac. II,VII, X: Coagulation factor II, VII and X]

\section{Author details}

'Optimed, Clinical Research Centre, Copenhagen University Hospital, Hvidovre, Denmark. ${ }^{2}$ Department of Public Health, Section of Biostatistics, University of Copenhagen, Copenhagen, Denmark. ${ }^{3}$ Department of Orthopedic Surgery, Copenhagen University Hospital, Hvidovre, Denmark. ${ }^{4}$ Department of Physical Therapy, Physical Medicine \& Rehabilitation Research - Copenhagen (PMR-C), Copenhagen University Hospital, Hvidovre, Denmark. ${ }^{5}$ The Emergency Department, Copenhagen University Hospital, Hvidovre, Denmark.

Received: 10 March 2017 Accepted: 10 March 2017

Published online: 15 March 2017

\section{Reference}

1. Klausen HH, Petersen J, Bandholm T, Juul-Larsen HG, Tavenier J, Eugen-Olsen J,

et al. Association between routine laboratory tests and long-term mortality among acutely admitted older medical patients: a cohort study. BMC Geriatr. 2017;17:62. 